criticisms which are at once rigorous and fair.

An introductory chapter outlines the issues both of personal morality and of public policy which lie behind the abortion debate. Sumner rightly identifies as the central problem whether and in what sense fetuses must be said to have a moral standing. He is well aware that it is far from easy to give a consistent and acceptable account of moral standing, and he wisely insists that any such account should be applicable to moral issues generally as well as to the particular range of problems with which he is concerned. This issue dominates the first four chapters of the book, and the clarity with which Sumner examines this question seems to me to be the principal merit of his book.

The second and third chapters set out, and in the end reject, both the liberal view that no fetuses have moral standing (or, in a weaker form, that no pre-viable fetus has moral standing), and the conservative view that all fetuses have full moral standing. He contends that the liberal view cannot convincingly explain why birth (or viability) should be such a significant point so far as acquisition of moral standing is concerned, and that the conservative view cannot make any better case for the significance of the moment of conception. In the course of his argument many other moral issues are discussed including the nature of moral rights; the various possible criteria for moral standing; the principle of double effect, and the relationship between the morality of abortion and the morality of selfdefence.

Sumner concludes that the failure of both positions derives from their shared assumption that all fetuses must have the same moral standing. Accordingly, his own middle way is to explore the possibility of denying this assumption, adopting instead a principle of moral standing which might differentiate between fetuses at various stages of their development. He concludes that the possession of sentience is the most reasonable basis for the attribution of moral standing. On the basis of neurophysiology, he holds that fetuses possess sentience certainly by the end of the second trimester, and certainly not before the beginning of that trimester. Accordingly, the crucial range for differentiating between fetuses falls in the second trimester.

The remainder of the book contains a more technical discussion of moral theory generally. Though Sumner's intention here is to provide a general

theory which would ground his views on abortion, moral philosophers would find his discussion interesting and original in its own right. It is to be hoped that those who would seek to defend a more liberal or a more conservative position than Sumner's will emulate the honesty and dispassionate objectivity which he brings to a discussion in which these virtues are all too often lacking.

GERARD J HUGHES

Heythrop College

University of London

\title{
Changing Patterns in Conception and Fertility
}

\section{F Roberts and R Chester \\ Academic Press, London, £ $_{10.40(\$ 25.00)}$}

This book makes fascinating reading. It is composed of twelve chapters, written by leading authorities, being the edited text of their lectures given at the I6th Annual Symposium of the Eugenics Society, held in September 1979.

The first section relates to fertility in its demographic context, highlighting the different problems in South America and the West and providing some explanation for the changes that have occurred.

Three chapters on the control of fertility will prove particularly interesting and useful for all those working in the field of family planning. Not only are the changes in contraceptive practice described but the risk/benefit considerations of the various methods currently available are expertly summarised in the light of present knowledge.

Some hope for the near future for improvement in contraceptive measures is presented clearly and critically in a chapter by Dr Howard Jacob. The extreme difficulty of introducing new methods, however, is also emphasised. Not only do there seem to be psychological difficulties in accepting the principle of Man controlling his fertility, demonstrated by those who campaign against contemporary methods stressing only their negative aspects, but many bureaucratic and financial influences also impede progress. Meanwhile the population explosion continues.

The newly-developing field of early detection of congenital abnormalities by the use of ultrasound and other screening measures is presented in a most encouraging manner: there is a real possibility that the numbers of seriously affected babies born may be reduced.

The chapter by Hawkins devoted to the effects of drugs in pregnancy and lactation is extremely comprehensive and helpful and provides a valuable guide for those clinicians who may need to prescribe under these conditions. An extensive list of references is included.

New problems encountered in contemporary society are faced in chapters on AID, teenage pregnancy, and the older parent. It is a pity, however, that no reference is made to the contraceptive problems of the older woman, nor any guidance given.

Well written, up-to-date and informative, this book is to be recommended for all clinicians working in any area of family planning (using the phrase in its widest sense to include infertility) as well as for demographers, social scientists and public health officials.

$$
\begin{array}{r}
\text { BARBARA LAW } \\
\text { formerly Chairman, } \\
\text { National Association of Family Planning }
\end{array}
$$
Doctors

\section{Legal Issues in Medicine}

\author{
Sheila A M McLean \\ Gower Publishing Company Ltd, \\ Aldershot, Hants \\ £i3.50
}

This collection of essays, of which more are by lawyers than doctors, certainly adds to the debate on difficult ethical questions as was its editor's intention.

Some repetition was perhaps inevitable, but more stringent editing would have spared the reader being taken over the same ground and being referred at length to the same case on a number of occasions. The references at the end of each chapter are full and informative, but do not in my view excuse the lack of an index.

The book is wholly Scottish but this should not deter the reader whose knowledge of Scots law may be minimal. Distinctions are clearly stated and in any event the book is more concerned with principles than with details of legislation or procedure. There should then be an appeal to all interested in medico-legal and ethical matters, but the appeal will be stronger to the lawyer and the law student than to the doctor, reflecting the predominance of legal contributors. 